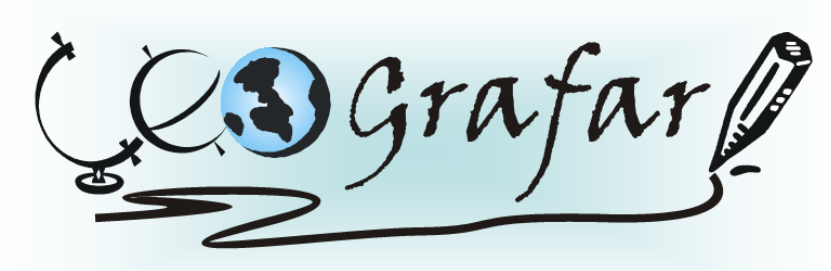

Revista Eletrônica do Programa de Pós-Graduação em Geografia - UFPR

\title{
A DINÂMICA E A CRISE DO COMÉRCIO NA CIDADE PEQUENA DE CARIRÉ $(\mathrm{CE})^{1}$
}

\author{
MARIA FERREIRA GOMES ${ }^{2}$ \\ LENILTON FRANCISCO DE ASSIS ${ }^{3}$
}

RESUMO: Este artigo apresenta algumas reflexões sobre o papel das cidades pequenas no contexto da rede urbana cearense. As mudanças e permanências no comércio das cidades pequenas do Norte Cearense instigaram uma análise específica do município de Cariré, onde, desde meados de 1950, com o colapso do algodão, o comércio da área central vivencia uma crise que se reflete no decréscimo demográfico e em toda a sua economia. A realidade de Cariré demonstra a complexidade e os diferentes papéis das cidades pequenas na rede urbana brasileira, as quais precisam ser mais investigadas nas suas especificidades e diversidades regionais.

Palavras-chave: comércio; cidade pequena; rede urbana.

\section{THE DYNAMICS AND THE CRISIS OF COMMERCE IN CARIRÉ SMALL CITY (CEARÁ STATE)}

\begin{abstract}
This article presents some reflections on the small city activities in the context of the Brazilian urban network. The changes and stays in small cities commerce of North Cearense instigated a specific analysis of the Cariré municipality. Since mid-1950 with the cotton collapse, commerce in the central area of Cariré experience a crisis that is reflected in the population and economic decline. Cariré case demonstrates the complexity and the different roles of small cities in the Brazilian urban network, which need to be further investigated in its peculiarities and regional diversities.
\end{abstract}

Key words: commerce; small city; urban net.

\footnotetext{
${ }^{1}$ Este artigo apresenta alguns dos resultados finais da pesquisa "As redes de comércio e serviço entre a cidade média de Sobral e algumas cidades pequenas da Região Norte do Ceará” (ASSIS, 2005; ASSIS, et. al, 2007) que desenvolvemos, entre 2005 e 2007, no Núcleo de Estudos Urbanos e Regionais (NEURB), do Curso de Geografia, da Universidade Estadual Vale do Acaraú (UVA-Sobral/CE), com o apoio da Fundação Cearense de Apoio ao Desenvolvimento Científico e Tecnológico (FUNCAP).

2 Licenciada em Geografia pela UVA (Sobral/CE); ex-bolsista do PBU/UVA e do NEURB; maria.f.gomes@hotmail.com Rua Francisco Gomes de Albuquerque, 1277, Alto São José, Coreaú-CE. CEP: 62160-000

${ }^{3}$ Professor Assistente do Curso de Geografia da UVA (Sobral/CE); Doutorando em Geografia Humana na USP; bolsista do CNPq - Brasil. lenilton@ yahoo.com Av. John Sanford, 1845, Junco, Sobral-CE. CEP: 62030-000.
} 


\section{INTRODUÇÃO}

O estudo das pequenas cidades no Brasil representa um desafio para a ciência geográfica que, historicamente, tem concentrado as suas reflexões sobre as transformações em curso nos espaços das metrópoles e, mais recentemente, das cidades médias.

Porém, as funções das pequenas cidades também precisam ser levadas em conta no contexto urbano e econômico brasileiro. Para tal fim, diversos "caminhos" e abordagens são possíveis.

Neste trabalho, o enfoque metodológico prioriza o comércio como um elemento constituinte do urbano que permite apreender a gênese e a dinâmica das pequenas cidades. $\mathrm{O}$ comércio revela a evolução do espaço urbano e das práticas de consumo da sociedade (PINTAUDI, 2002).

Busca-se refletir sobre o papel dos pequenos centros no contexto da rede urbana brasileira e, em especial, do Norte Cearense, onde destacamos a cidade pequena de Cariré (Figura 1).

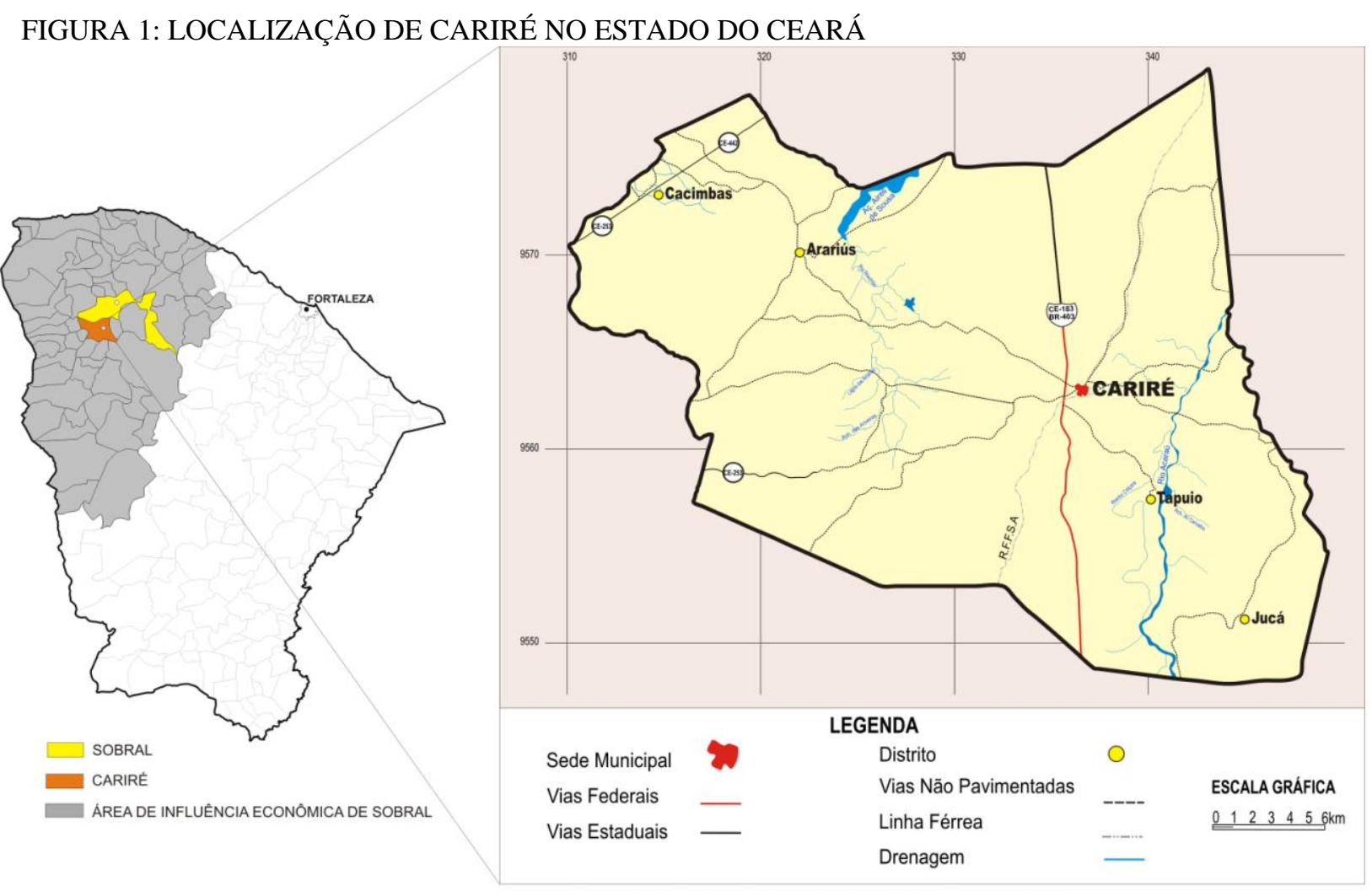

Fonte: Adaptado do IPECE, 2004. Organizaçäo: Francinelda Araújo, 2008. 
Em Cariré, o comércio da área central vivencia uma crise em virtude do agravamento da pobreza da população que, na sua maioria, é formada de agricultores. $O$ entendimento da crise de Cariré prescinde de uma análise das redes de comércio que esta pequena cidade estabelece com os distritos e as maiores aglomerações do Norte cearense, especialmente com Sobral.

Nessa perspectiva, apresentamos a seguir algumas considerações sobre o comércio das cidades pequenas do Norte do Ceará, tendo como subsídios a realização de uma pesquisa bibliográfica sobre a temática em apreço e a coleta de dados e informações sobre alguns municípios da região. Realizamos ainda trabalhos de campo em Cariré, onde mapeamos o comércio da área central e aplicamos entrevistas semi-estruturadas com comerciantes, moradores e motoristas de topicks.

\section{O COMÉRCIO DAS CIDADES PEQUENAS: CONSIDERAÇÕES SOBRE O NORTE CEARENSE}

No Brasil, as cidades pequenas de até 20.000 habitantes ainda são maioria no total de aglomerados urbanos. No Censo Demográfico de 2000, essa classe de cidade já representava $73,07 \%$ (4.024) do total de municípios (5.507) do país, conforme os dados do Instituto Brasileiro de Geografia e Estatística (IBGE, 2008).

Muitos estudiosos utilizam a expressão cidades pequenas como sinônimo de municípios pequenos, denunciando a ausência de um consenso metodológico no país. Eles não esclarecem se o universo considerado corresponde à população total do município (urbana e rural), à população urbana (da cidade e das vilas) ou apenas à população da cidade (sede do município).

Os parâmetros demográficos (mínimos e máximos) para classificar as cidades no Brasil também divergem entre os órgãos oficiais de estatística (IBGE e IPEA), os especialistas (WANDERLEY, 2001; VEIGA, 2002; SANTOS, 2005) e os adotados em outros países (BRAGA, 2004).

O Instituto de Pesquisa Econômica Aplicada (IPEA), por exemplo, designa como cidades pequenas os centros com população total de até 50.000 habitantes; classificação esta 
que é compartilhada por Corrêa (1999). Já para o IBGE, as cidades pequenas são aquelas com uma população inferior a 100 mil habitantes.

Wanderley (2001) trabalha com o conceito de "pequenos municípios", diferenciando duas categorias: os que possuem uma população total inferior a 20.000 habitantes e os cuja população total é superior, mas apresentam uma população urbana que não ultrapassa este limite.

O imperativo estatístico para classificar as cidades pequenas já se apresentava, no final da década de 1970, como uma "generalização perigosa", apontada por Santos (1982, p. 69), que preferia usar o termo "cidade local" ao invés de cidade pequena. Para este autor, "a cidade local é a dimensão mínima a partir da qual as aglomerações deixam de servir às necessidades da atividade primária para servir às necessidades inadiáveis da população, com verdadeira especialização do espaço" (SANTOS, 1982, p. 71).

Pensar nessa "dimensão mínima" de cidade não é restringir sua condição ao contingente populacional (embora esse seja um elemento importante), mas também considerar a vida de relações construídas com os distritos e os demais aglomerados do entorno.

Em trabalhos posteriores, Santos $(1998 ; 2005)$ analisou como as cidades locais mudam de conteúdo com a expansão do meio técnico-científico-informacional, transformando-se em "cidades econômicas" ou "cidades do campo".

\begin{abstract}
A cidade torna-se o locus da regulação do que se faz no campo. É ela que assegura a nova cooperação imposta pela nova divisão do trabalho agrícola, porque obrigada a afeiçoar-se às exigências do campo, respondendo às suas demandas cada vez mais prementes e dando-lhe respostas cada vez mais imediatas. Como o campo se torna extremamente diferenciado pela multiplicidade de objetos geográficos que o formam, pelo fato de que esses objetos geográficos têm um conteúdo informacional cada vez mais distinto (o que se impõe, porque o trabalho no campo é cada vez mais carregado de ciência), tudo isso faz com que a cidade local deixe de ser a cidade no campo e transforme-se na cidade do campo (SANTOS, 2005, p. 56-57).
\end{abstract}

Todavia, esta modernização propiciada pela inserção das cidades pequenas na globalização é desigual e seletiva, não sendo um processo homogêneo para todo o território brasileiro.

A industrialização do campo, a urbanização, o aumento da acessibilidade, a penetração de capitais externos, a exclusão da modernização e o agravamento das condições de vida no mundo agrícola criaram diversas realidades das cidades pequenas brasileiras no final do 
século XX. Essa diversidade levou Corrêa (2007, p. 7) a apontar cinco padrões funcionais que caracterizarão esses pequenos centros nos primeiros 25-30 anos do século vigente. Resumimos abaixo esses cinco padrões, considerando a advertência do autor de que entre eles pode haver combinações:

1. Prósperos lugares centrais em áreas submetidas à industrialização do campo; são as típicas "cidades do campo";

2. Pequenos centros funcionalmente especializados a partir de capitais locais ou de capitais de grandes empresas sediadas externamente que promovem uma reinserção da pequena cidade na rede urbana, substituindo com sucesso uma centralidade que entrou em declínio;

3. Pequenas cidades que se tornam extensões funcionais das cidades maiores, transformando-se em subúrbios-dormitórios onde predominam as migrações pendulares entre casa e trabalho.

4. Focos de concentração de trabalhadores agrícolas que foram, em muitos casos, antigos lugares centrais afetados pelas transformações agrárias;

5. Núcleos dependentes de recursos externos. São pequenas cidades pobres e esvaziadas, de onde jovens e muitas famílias emigraram.

De maneira geral, podemos dizer que os dois primeiros padrões são mais freqüentes nas cidades pequenas do Centro-Sul do país; e os três demais são mais comuns no NorteNordeste. Os cinco padrões acima (que ainda podem ser complementados) acenam a diversidade de funções exercidas pelas cidades pequenas na rede urbana brasileira e esboçam um grande desafio para os técnicos e estudiosos urbanos definirem uma metodologia que contemple essa heterogeneidade.

Nesse sentido, Soares e Melo (2005, p. 6) advertem que "a definição de parâmetros nacionais rígidos para classificação e definição desses espaços pode incorrer em sérios problemas impedindo uma melhor aproximação com a realidade sócio-espacial, dada à complexidade e diversidade do espaço brasileiro".

Podemos dizer que as cidades locais, caracterizadas acima por Santos (2005), são mais encontradas na "região concentrada" do país, onde a modernização agrícola, associada à industrialização em curso, tem resultado na formação dos complexos agroindustriais - como no Norte do Paraná (FRESCA, 2001) e no Triângulo Mineiro e Alto Paranaíba-MG (OLIVEIRA; SOARES, 2002). 
No Norte Cearense, a maioria dos pequenos centros polarizados pela cidade média de Sobral (Figura 1), ainda tem suas economias assentadas na agropecuária extensiva, no "comércio primitivo" e na oferta dos serviços básicos e administrativos. Eles dependem de Sobral para se abastecer de um comércio diversificado, de serviços especializados e, principalmente, de trabalho.

Por isso, preferimos adotar nesta análise a terminologia "cidades pequenas" (mesmo reconhecendo as suas limitações), pois consideramos que os pequenos centros do Norte Cearense (especialmente Cariré que discutiremos adiante) não se enquadram no perfil das cidades locais propostas por Santos $(1998 ; 2005)$.

Conhecer melhor a realidade sócio-espacial das cidades pequenas de cada região do país é um caminho para se construir, no futuro, uma ou várias metodologias que abarquem a diversidade regional.

Uma cidade com um contingente populacional de 20.000 habitantes, localizada no Nordeste brasileiro, apresenta características econômicas, políticas e sociais que podem ser vistas como consequiência dos problemas "típicos" da região como carência de emprego, baixos índices de saúde, educação, etc. Bem diferente pode ser a situação de uma outra cidade, também com 20.000 habitantes, localizada nas regiões Sul e Sudeste, onde a concentração de grandes indústrias, a melhor distribuição de renda e o maior volume de investimentos públicos e privados lhe possibilita uma melhor oferta de serviços do que suas similares do Nordeste.

Há também cidades pequenas que não se enquadram no padrão regional "predominante" e que tanto integram os vales irrigados da moderna agricultura para exportação, no Nordeste; assim como, as áreas de seca e pobreza dos Pampas Gaúchos e do Vale do Jequitinhonha, no Sul-Sudeste.

Por isso, devemos estudar as cidades pequenas brasileiras, considerando suas especificidades e diversidades, através de parâmetros que abarquem além do tamanho populacional, as origens, o cotidiano, as atividades econômicas e, especialmente as funções regionais - como propomos para Cariré.

Não podemos desprezar as importantes funções que as cidades pequenas exercem na rede urbana regional e nacional, assim como as relações que elas engendram com os distritos e as zonas rurais do seu entorno. "Essa capacidade das cidades pequenas responderem às 
necessidades vitais da população é um dos elementos que garante a existência e o funcionamento de tais cidades" (SANTOS, 1979, p. 71).

Deste modo, ao analisarmos as pequenas cidades do Norte do Ceará (mais especificamente Cariré que está na área de influência de Sobral), é necessário levarmos em conta as particularidades regionais do ambiente, haja vista esta região sertaneja possuir características marcantes nas suas relações comerciais, desde o fim do século XVII e início do século XVIII, quando passou a ser ocupada com as primeiras fazendas de gado nas margens do rio Acaraú e de seus afluentes mais importantes (MARIA JÚNIOR, 2004, p. 29).

As heranças do "ciclo" do gado ainda são visíveis em muitas feiras livres do Norte Cearense, onde são freqüentes a venda de alimentos, vestimentas, calçados, acessórios e utensílios domésticos que retratam, até hoje, a importância econômica da pecuária para as pequenas cidades da região.

O comércio, nessas pequenas cidades, ainda se desenvolve de maneira "tradicional", o que não significa que esteja alheio à "modernização", à inovação e à imitação dos centros maiores de que depende e se abastece. Já é crescente, a "invasão" dos "importados" e "eletrônicos" em muitas feiras livres, armarinhos e mercearias.

A área central da pequena cidade ainda concentra grande parte do comércio e das residências. É lá também onde se encontra a igreja matriz, a prefeitura e o maior movimento de pessoas que, atraídas pela missa no domingo ou qualquer outra manifestação cultural, aproveitam para comprar a carne na banca do mercado, o açúcar e o arroz nas bodegas e mercearias e algumas peças de roupas nas pequenas lojas de confecção.

Muitos ainda adotam a caderneta de "fiado" como registro das compras que devem ser pagas dias depois ou no mês seguinte. É importante destacar que estas manifestações da "pessoalidade" nas pequenas cidades são sempre baseadas nas relações de confiança e amizade entre o comerciante e o freguês. Elas também denotam a predominância do "circuito inferior" na economia desses pequenos centros, já que:

Para o consumidor, que é, com mais freqüência, pobre e sem emprego permanente, o crédito representa uma necessidade imperiosa. Sem ele seria impossível prover as necessidades da família; o trabalho temporário ou ocasional só permite entradas esporádicas de dinheiro. [...] Somente o pequeno comércio do circuito inferior está adaptado às condições da clientela pela venda a crédito e pelo fracionamento das mercadorias (SANTOS, 1979, p. 188). 
É na área central da cidade pequena onde essas relações comerciais adquirem maior expressão, já que o centro é, de fato, o "coração" e o "cérebro" do pequeno núcleo urbano. “[...] Constitui-se no foco principal não apenas da cidade, mas também de sua hinterlândia. Nela concentram-se as principais atividades comerciais, de serviços, da gestão pública e privada, e os terminais de transportes inter-regionais e intra-urbanos [...]" (CORRÊA, 2002, p. $38)$.

O mercado público e a feira livre são outras duas importantes instituições comerciais das pequenas cidades. Ambas estiveram sempre presentes em seu cotidiano, estando concentradas também na área central, desenvolvendo os mais diversos tipos de comércio, como a venda de gêneros alimentícios, frutas, peixes e comidas típicas, etc. Nos dias de feira, as pequenas cidades nordestinas ganham uma nova feição. Em algumas delas, é difícil distinguir até que ponto a feira depende da cidade ou a cidade da feira (ISSLER, 1967).

A feira aumenta o fluxo de pessoas vindas das localidades circunvizinhas e das áreas rurais para comprar e vender mercadorias. Como ressaltam Gonçalves e Dantas (2005, p. 4):

\footnotetext{
Realizadas uma vez por semana, as feiras livres têm a função de congregar diversos negócios e concentram grande parte da produção regional, realizando assim, o abastecimento das populações que moram nos núcleos urbanos e nas áreas rurais. Estes eventos também representam um espaço de integração social e de manifestações. Geralmente, as feiras estão integradas ao mercado público e são realizadas na área central de tais cidades e na praça da matriz ou na rua principal.
}

Outra característica importante das pequenas cidades da região Norte do Ceará é a predominância da agricultura familiar, cuja produção é, em parte, destinada ao comércio nas feiras (feijão, farinha, milho), onde o pequeno produtor, muitas vezes, não vende diretamente aos consumidores, mas a outros comerciantes da cidade que compram essa produção a um preço menor e revendem na feira ou em estabelecimentos de sua propriedade.

No passado, essa relação agricultura-comércio era mais forte especialmente por causa do algodão, cuja produção atingiu seu auge no Ceará entre a segunda metade do século XIX e meados do século XX (SILVA, 2000).

Nesse período, surgiram firmas comerciais nas cidades de Granja e Camocim, cuja atividade principal era a exportação de algodão para a Inglaterra e Estados Unidos através do porto de Camocim. Essas firmas realizavam transações comerciais com os pequenos estabelecimentos sediados nas pequenas cidades e vilas da região Norte do Ceará. Estes 
compravam o algodão em caroço diretamente do pequeno agricultor e revendiam para essas firmas exportadoras. Na maioria das vezes, os comerciantes da cidade eram também proprietários rurais que cultivavam o algodão que era revertido para o estoque do seu estabelecimento. Ao mesmo tempo, compravam também a produção dos seus moradores e de outros pequenos agricultores que passaram a praticar a agricultura comercial ao lado da agricultura de subsistência.

Essa inserção do trabalhador rural na agricultura comercial foi motivada pela grande possibilidade de lucro representada pelo algodão que passou a ser um importante produto de exportação. O principal destino era os Estados Unidos, cuja produção havia cessado em decorrência da Guerra de Secessão.

Diante da crescente procura pelo algodão, as pequenas cidades da região Norte do Ceará viram surgir a possibilidade de um crescimento econômico, uma vez que, segundo Medeiros (2000, p.17), "as condições climáticas do Nordeste favoreciam a expansão da cultura algodoeira, permitindo o cultivo do algodão Mocó ou Seridó, que é um algodão de fibra longa, melhor utilizada industrialmente, fato que lhe conferia altos preços no mercado". De fato, o algodão, a pecuária, a mamona e a oiticica propiciaram o desenvolvimento econômico de muitas cidades do Norte do Ceará.

Atualmente, várias dessas cidades experimentam o declínio de sua economia dada à diminuição da produção do algodão e dos outros produtos agrícolas. Esse declínio tem, consequentemente, repercussões no comércio dessas pequenas cidades que, cada vez mais, tornam-se dependentes da cidade média de Sobral, para onde recorrem diariamente em busca de empregos, comércio diversificado e serviços especializados (ASSIS, 2005). Sobral é o "pólo regional" do Norte do Ceará que influencia cerca de cinqüenta municípios do seu entorno (HOLANDA, 2000).

Estes pequenos municípios formam com Sobral um “[...] conjunto de centros urbanos funcionalmente articulados entre si [...]" (CORREAA, 2001, p. 93), e simultaneamente integrados a outras redes (regional, nacional e mundial).

No Ceará, a rede urbana é marcada pela “[...] fraca articulação entre as cidades e a forte concentração urbana na capital e mais recentemente em sua área metropolitana, o crescimento das cidades de nível intermediário e a pouca capacidade de articulação dos centros locais." (AMORA, 1999, p. 30). Neste sistema de cidades, Sobral se configura como um centro 
funcional intermediário, um nó intersticial que articula os fluxos entre as pequenas cidades e a metrópole regional (Fortaleza).

Nas pequenas cidades da hinterlândia de Sobral, a atividade agrícola passou a se voltar quase que totalmente para a agricultura de subsistência, sendo o pouco excedente da produção levado para venda nas feiras. O comércio ocupa lugar de destaque na economia local, apesar de apresentar características bastantes "primitivas" (SANTOS, 1979). Uma delas é a predominância do emprego do "dinheiro vivo" como forma de pagamento, ficando quase que totalmente ausentes outras formas como o cheque e o cartão de crédito.

A aceitação do cheque está sempre condicionada à confiança interpessoal entre comerciante e cliente, já que na maioria das pequenas cidades não existe associação de proteção ao crédito.

O uso do cartão de crédito também é limitado pela "desconfiança" do próprio comerciante a respeito da segurança destas transações. Muitos acreditam que poderão ter algum prejuízo ou mesmo a sua margem de lucro reduzida ao aceitar o pagamento através do cartão. Em algumas pequenas cidades, o cartão de crédito é aceito apenas nos postos de combustíveis, já que esses precisam vender a muitos viajantes.

Desse modo, essas mudanças e permanências no comércio das cidades pequenas do Norte Cearense nos instigam a fazer, em seguida, uma análise específica do município de Cariré, onde, desde meados de 1950, com o colapso do algodão, o comércio da área central vivencia uma crise que se reflete no decréscimo demográfico e em toda a sua economia.

\section{A DINÂMICA E A CRISE DO COMÉRCIO DE CARIRÉ}

No Norte Cearense, muitas cidades (como Cariré, Sobral, Uruoca, Camocim e Acaraú) surgiram como entrepostos comerciais beneficiados pelo desenvolvimento dos meios de transporte, especialmente do trem que, no século XIX, tinha a função de escoar a produção do interior para os grandes portos do litoral do país. Elas se tornaram "nós de trafego" ou "pontas de trilhos" (gateways cities), como chama Corrêa (2007).

Em Cariré, a inauguração da estação ferroviária da Rede de Viação Cearense (RVC), em novembro de 1891, deu significativo impulso econômico à cidade, visto que foi a partir desse momento que ela começou a crescer e a desenvolver as primeiras trocas comerciais. 
Situado em pleno sertão semi-árido, na porção Noroeste do Estado do Ceará, Cariré é um pequeno município com 18.617 habitantes (segundo o Censo 2000), distante $42 \mathrm{~km}$ de Sobral e $273 \mathrm{~km}$ de Fortaleza. Cariré possui uma considerável extensão territorial de 757 km², o que contribui para a distribuição da população entre a cidade (sede do município), os demais distritos (Arariús, Cacimbas, Jucá e Tapuio) e a maior concentração na zona rural - Figura 1.

O município de Cariré foi criado em 1929 e voltou a ser distrito de Sobral em 1931. Somente em 1938 foi elevado, definitivamente, à categoria de município. Durante os anos em que foi distrito, Cariré se beneficiou da riqueza de Sobral com a exportação da carne e do couro e, sobretudo com o comércio do algodão. Com a cultura do algodão, Cariré começa a sentir os primeiros efeitos do progresso, juntamente com a cera de carnaúba, a oiticica, a mamona e cereais como o arroz e o milho que complementavam a produção.

O algodão era o principal artigo da produção agrícola do município e de toda a região. A produção de algodão em Cariré era tão grande que foram construídos, além da ferrovia, alguns armazéns e duas fábricas de beneficiamento deste produto. O caroço do algodão servia de ração para o gado e a lã era levada de trem para Sobral, depois seguia para o porto de Camocim, onde de navio era transportada para Fortaleza ou diretamente exportada para as fábricas de tecidos nos Estados Unidos.

Os americanos consideravam o algodão cearense o melhor do mundo. Com isso, o município de Cariré crescia e (re)definia seu espaço, visto que muitas pessoas chegavam para trabalhar na produção do algodão e acabavam fixando residências. Surgia, assim, a necessidade de um comércio mais diversificado para atender às necessidades da crescente população.

O comércio do centro foi demonstrando sinais de progresso e a produção agrícola baseada no algodão, cera de carnaúba, oiticica, castanha de caju e mamona, movimentava bastante a economia local, ao lado das bodegas, mercearias, padarias e lojas de tecidos, como bem afirma Padre Heleno, citado por Medeiros (2000, p.63):

Tenho a impressão de que o comércio local se bastava a si mesmo, satisfazendo o consumo [...] ao lado das bodegas e mercearias, muitas lojas de tecidos. Lembro algumas: 'A Vendedora', de Antônio Rodrigues Filho, 'A Graciosa', de Antônio Honório de Brito, 'A Perseverante', de Joaquim Saturnino de Araújo, 'Casa Sambeneditense', de Ximenes Rodrigues, e mais as lojas de João Tomás de Vasconcelos, Augusto Rocha, Elízio Aguiar e algumas outras. 
Percebe-se, na citação acima, que Cariré, no auge da produção algodoeira, tornou-se um município próspero, dando condições para seu desenvolvimento e expansão comercial, e com possibilidades de acolher inúmeras pessoas que chegavam. Em 1950, o município já registrava um total de 21.020 habitantes, sendo $91,28 \%$ residentes na zona rural e $8,71 \%$ na zona urbana (IBGE, 2008).

É importante ressaltar que, durante as primeiras décadas do século XX, a produção agrícola no Nordeste brasileiro foi de grande relevância para o progresso de pequenos núcleos urbanos, visto que, na época, a tecnologia ainda não tinha alcançado o campo e a produção favorecia a uma camada maior da população. A carência dos transportes dificultava o acesso aos maiores centros, favorecendo o desenvolvimento da economia regional e o comércio entre as cidades pequenas.

Em Cariré, no auge da produção do algodão, além das duas indústrias de beneficiamento do produto, surgiram outras de beneficiamento do arroz, do milho e a indústria artesanal, sobretudo de chapéu de palha. O município chegou a registrar quinze indústrias instaladas, segundo Medeiros (2000, p. 64).

Nessa época, a feira da cidade era bem desenvolvida e comercializava produtos da região, tais como: farinha, feijão, frutas, sal, etc., com a presença significativa dos comboieiros que traziam seus produtos para serem comercializados e, com o lucro obtido, compravam outras mercadorias no comércio local. O comércio da cidade se intensificava nos dias de feiras.

Dessa forma, a pequena cidade de Cariré, por alguns anos, desenvolveu um comércio promissor e suficiente para abastecer o consumo da população, não sendo necessário recorrer aos centros maiores em busca de outros produtos, pois tudo que necessitavam encontrava-se no comércio local.

A partir da década de 1970, os pequenos núcleos urbanos do Ceará que tinham sua economia voltada para a produção agrícola, viram-se diante da crise que o setor estava passando. O algodão deixava de ser produzido, causando inúmeras transformações nas relações de produção, como reforça Medeiros (2000, p. 41).

Diante da quebra do algodão causando inúmeras mudanças nas relações de produção, toda a economia do semi-árido foi abalada gerando uma intensa crise econômica que perdura até hoje. As drásticas mudanças no sistema produtivo afetaram o semi-árido de forma global, atingindo de forma particular a economia de pequenos centros municipais e estes reagem de acordo com sua especificidade e exprimem em sua organização as marcas de tal crise [...]. 
Com a modernização do campo, em algumas localidades do país, e a falta de incentivos à agricultura familiar, esta foi perdendo espaço, acarretando o êxodo rural de grande parte da população que, na tentativa de se inserir nas atividades desenvolvidas nas áreas urbanas, migrava para as cidades.

Em Cariré, parte da população do campo migrou para a sede do município, Sobral, Fortaleza e outros Estados do país. Isto desencadeou um decréscimo populacional no município que, em 1950 tinha 21.020 habitantes e, no Censo 2000, registrou apenas 18.617 pessoas (Tabela 1).

\begin{tabular}{c|c|c|c|c|c}
\multicolumn{6}{c}{ TABELA 1: EVOLUÇÃO DA POPULAÇÃO DE CARIRÉ - 1950/2000 } \\
\hline Ano & Pop. Total & Urbana & $\%$ & Rural & \% \\
\hline 1950 & 21.020 & 1.831 & 8,71 & 19.189 & 91,28 \\
\hline $1960 *$ & 17.560 & 1.814 & 10,33 & 15.746 & 89,66 \\
\hline 1970 & 18.410 & 1.835 & 10 & 17.575 & 90 \\
\hline 1980 & 18.311 & 2.988 & 16,31 & 15.373 & 83,95 \\
\hline 1991 & 17.755 & 3.822 & 21,52 & 13.933 & 78,47 \\
\hline 2000 & 18.677 & 5.459 & 29,32 & 13.158 & 70,68 \\
\hline
\end{tabular}

Fonte: IBGE, 2008. Base de Dados Agregados - SIDRA. Elaboração dos autores Censos Demográficos - 1950, 1970, 1980, 1991, 2000.

Contagem da População - 1996. *Sinopse Preliminar do Censo Demográfico 1960.

Ao longo desse período, a população urbana aumentou de $8,71 \%$ para $29,32 \%$. Por outro lado, a população rural diminuiu, sobretudo em virtude da queda na produção agrícola, que gerava emprego e renda para o município. Mas, a população do campo ainda se apresenta bastante significativa, representando quase três quartos $(70,68 \%)$ do total de habitantes em 2000 (Tabela 1).

Na última Contagem da População, em 2007, o ritmo decrescente da população persiste, levando o município a registrar um total de 18.527 habitantes (IBGE, 2008). Esse quadro demográfico, mesmo não sendo suficiente, é um indicativo da crise que afeta a economia do município - conforme atestam os dados seguintes.

O PIB de Cariré, em 2005, indicou uma pequena participação da indústria (9\%) na geração das riquezas do município, seguida pela agropecuária $(21 \%)$ e pelos serviços $(70 \%)$, este último com maior destaque. No entanto, a agropecuária é o setor de atividades que mais 
emprega em Cariré, sendo responsável pela ocupação de mais da metade da mão-de-obra do município (Tabela 2).

TABELA 2: PESSOAS DE 10 OU MAIS ANOS OCUPADAS POR SEÇÃO DE ATIVIDADE - CARIRÉ 2000

\begin{tabular}{l|c|c}
\hline ATIVIDADES & $\mathbf{N}^{\mathbf{0}}$. Absolutos & $\mathbf{\%}$ \\
\hline Agricultura, pecuária, silvicultura e exploração florestal & 3.827 & 57,54 \\
\hline Pesca & 44 & 0,66 \\
\hline Indústria de Transformação & 539 & 8,10 \\
\hline Produção e distribuição de eletricidade, gás e água & 13 & 0,19 \\
\hline Indústria de Construção Civil & 189 & 2,84 \\
\hline $\begin{array}{l}\text { Comércio, reparação de veículos automotores, objetos } \\
\text { pessoais e domésticos }\end{array}$ & 433 & 6,51 \\
\hline Alojamento e alimentação & 226 & 3,40 \\
\hline Transporte, armazenagem e comunicação & 63 & 0,94 \\
\hline $\begin{array}{l}\text { Atividades imobiliárias, aluguéis e serviços prestados às } \\
\text { empresas }\end{array}$ & 69 & 1,04 \\
\hline Administração pública, defesa e seguridade social & 554 & 8,33 \\
\hline Educação & 244 & 3,67 \\
\hline Saúde e serviços sociais & 45 & 0,68 \\
\hline Outros serviços coletivos, sociais e pessoais & 64 & 0,97 \\
\hline Serviços domésticos & 333 & 5,00 \\
\hline Atividades mal especificadas & 8 & 0,12 \\
\hline Total & $\mathbf{6 . 6 5 0}$ & $\mathbf{1 0 0}$ \\
\hline \multicolumn{1}{|c|}{ For } & 63 &
\end{tabular}

Fonte: IBGE, 2008. Base de Dados Agregados - SIDRA. Elaboração dos autores.

Dados do Censo Demográfico 2000.

Grande parte das ocupações na agropecuária ocorre com as lavouras temporárias de subsistência (milho, feijão e mandioca) e a pecuária extensiva para a criação de bovinos e, sobretudo de caprinos. No Censo Agropecuário de 1996, foram registradas 5.097 pessoas ocupadas principalmente na pecuária $(48 \%)$ e nas lavouras temporárias $(24 \%)$. Porém, os dados preliminares do Censo Agropecuário de 2006 indicam um total de 4.539 pessoas empregadas em estabelecimentos agropecuários em Cariré, ou seja, uma redução de 558 ocupações entre 1996 e 2006.

Além da agropecuária, as atividades de comércio e serviço também se destacam no município (Tabela 2) e se considerarmos o número de trabalhadores "informais" nelas ocupados (como os feirantes, por exemplo), podemos entender a importância dessas atividades para geração de emprego e renda em Cariré.

Todavia, essa "terciarização" da economia de Cariré não resulta, apenas, da urbanização do município, mas também do enfraquecimento e da fragilidade dos demais setores 
(agropecuária e indústria) que vêm transformando o comércio e os serviços nas principais “alternativas" para a pobreza e o desemprego (ASSIS et al., 2007).

Os órgãos públicos estaduais e a Prefeitura são as principais fontes de emprego nos serviços administrativos, principalmente, nas escolas e hospitais. Como alerta Assis (2005, p. 1287), “esta é uma estratégia política 'corriqueira' em diversos pequenos municípios brasileiros, onde as elites locais perpetuam o status quo dominante através da criação e da distribuição de empregos temporários entre parentes e aliados políticos”.

O comércio e os serviços de Cariré sentem a crise da agropecuária. Muitas lojas de tecidos, casas comerciais e indústrias de beneficiamento fecharam as portas no município, seguidas também pela agência do Banco do Brasil, em 1980. Atualmente, o município possui uma agência do Bradesco e uma Lotérica da Caixa Econômica Federal que possuem um baixo volume de operações, sendo grande parte das receitas provenientes dos pagamentos dos funcionários públicos, aposentados, pensionistas e programas de auxílio social do Governo Federal.

No final de 2005, o Bradesco comprou o até então Banco do Estado do Ceará (BEC), incorporando suas 69 agências no Estado, dentre as quais a de Cariré. Diante das críticas e pressões populares para a manutenção do BEC, um dos acordos firmados pelo Bradesco foi de permanecer com todas as agências e seus funcionários. A agência de Cariré ainda se mantém, mesmo com um baixo número de operações de crédito (em 2007, foram 36.546,69 reais, segundo o Banco Central do Brasil), sendo a maioria de depósitos à vista do governo estadual e municipal.

Predomina, em Cariré, um pequeno comércio varejista concentrado na área central da cidade, no entorno do mercado público que é delimitado pelas ruas Sebastião Miranda, Berlamina Rodrigues, Enrique Rodrigues e Cefisa Aguiar. Nesta área, identificamos (em trabalho de campo realizado em abril de 2005) 22 estabelecimentos varejistas, dos quais se destacava o comércio "primitivo" das bodegas e mercearias de gêneros alimentícios e bebidas (36\%), acompanhado pela venda de tecidos e artigos para confecção (18\%), produtos farmacêuticos (14\%), combustíveis e peças para veículos (14\%), ferragens (9\%) e máquinas, aparelhos elétricos e não elétricos (9\%).

Nas entrevistas, os comerciantes antigos da cidade recordaram o progresso que já houve no município. Atualmente, muitos moradores beneficiados pela melhoria dos meios de 
transporte, que reduziu o tempo e o custo das passagens, deslocam-se diariamente para a cidade média de Sobral, onde o comércio é mais pujante e atrativo.

Eu tinha aqui na cidade quatro estabelecimentos comerciais: farmácia, padaria, lojas de tecido e sapataria. Naquela época, as pessoas não iam comprar em Sobral, porque o único transporte disponível era o trem e o cavalo. [...] Sobral tem um comércio mais moderno, mais diversificado, tem um menor preço. Os novos comércios que surgiram em Cariré, as bodegas, os mercadinhos não suportam a concorrência com Sobral (Comerciante, 86 anos).

Hoje, o comércio demonstra sempre uma queda porque aqui é uma vergonha. Quem sustenta o comércio são os aposentados. O pessoal que trabalha na Prefeitura compra a maior parte é em Sobral (Comerciante, 80 anos).

O dinheiro que gira no comércio de Cariré é somente dos aposentados, no período do $1^{o}$ ao $12^{\circ}$ dia do mês. A partir daí, o comércio de Cariré pára (Comerciante, 26 anos).

Nos últimos anos, além do fechamento de alguns estabelecimentos, as mudanças observadas no comércio de Cariré correspondem às reformas no interior de algumas bodegas, armarinhos e mercearias que, gradativamente, vêm acrescentando caixas registradoras e retirando o tradicional balcão que separava o cliente da mercadoria, oferecendo o serviço de auto-atendimento. Só o maior mercantil da cidade possui computador e um caixa eletrônico do Bradesco.

O galpão da área central que abriga a feira livre, nas terças, foi reformado, em 1998, e, recentemente, foi feita uma enquete com a população que aprovou a mudança do dia da feira para o sábado, a partir de 2009. Com essa mudança, a prefeitura espera incentivar um maior número de agricultores e pecuaristas de Cariré a venderem seus produtos na feira, diminuindo a participação de comerciantes dos municípios adjacentes (que são maioria), os quais terminam levando parte da renda local para os seus lugares.

No entanto, o mercado público municipal que é o principal centro comercial de Cariré ainda se encontra em reformas, desde 2006, contribuindo para que muitos pequenos comerciantes desistam de manter ali seus negócios, diante da falta de condições físicas e de higiene.

No tocante aos serviços, em Cariré, funcionam apenas os que atendem às necessidade básicas da população. Constatamos, nos trabalhos de campo, que havia um total de trinta e duas escolas municipais, uma estadual e uma particular que oferecem a Educação Básica. Muitas dessas escolas funcionam nos distritos e zonas rurais, com apenas duas salas de aula 
para as séries inicias. As aulas ocorrem, na maioria, durante a manhã e a tarde, pois em algumas localidades ainda não têm energia elétrica, impedindo que as escolas também funcionem à noite.

Existem apenas duas escolas que ofertam o Ensino Médio em Cariré e muitas pequenas escolas dos distritos e povoados estão sendo fechadas por não conseguirem alunos suficientes para formar novas turmas. Uma das explicações para esse problema é que a população dos distritos e povoados mais afastados da sede de Cariré vem preferindo matricular as crianças e jovens nos municípios mais desenvolvidos, próximos das suas residências, que oferecem mais opções de ensino e de deslocamento. Além da educação básica, alguns moradores de Cariré recorrem a outras cidades (sobretudo a Sobral) à procura de cursos língua, informática, preparatórios, profissionalizantes e superiores.

As opções de transporte são as três linhas de ônibus intermunicipais, quatro interestaduais e as várias topicks que, a cada ano, crescem no município, como atesta o depoimento abaixo:

Eu faço duas viagens por dia e a cada viagem levo mais ou menos meia hora. Mas, em média, diariamente 30 topicks se deslocam da cidade com destino a Sobral, com intervalos entre 20 a 30 minutos e também o ônibus da Empresa Horizonte que passa em Cariré duas vezes por dia (Motorista de topick, 26 anos).

Na saúde, Cariré conta com nove unidades (1 hospital, 2 postos, 5 centros de saúde e 1 ambulatório) e com a grande carência de serviços médicos especializados. Há apenas clínicos gerais e enfermeiros. Até 2005, não havia sequer serviços de raio X ou de odontologia na rede pública municipal (CEARÁ, 2005). Os casos mais graves são encaminhados à Santa Casa da Misericórdia de Sobral que, em 2002, registrou o atendimento de 3.050 pacientes oriundos de Cariré. Conforme os moradores entrevistados, há também uma procura significativa pelos serviços do Hospital do Coração, das clínicas oftalmológicas e odontológicas de Sobral.

Sobral é a "cobertura" de Cariré. Você adoece, vai para Sobral. Se opera, tem médico, tem tudo. Aqui tem um hospital, mas não tem um médico "operador”, não tem nada. A "cobertura" de Cariré ainda é Sobral. Tudo que a gente quer vai lá... Aqui é muito fraco (Morador, 70 anos).

O colapso econômico provocado pela crise da agricultura tem contribuído para o "desmonte" do comércio e dos parcos serviços oferecidos à população que, cada vez mais, torna-se dependente da cidade média de Sobral. Por alguns anos, Cariré passou a ser 
apelidada de "cidade fantasma", pois o número de casas abandonadas era crescente, além das indústrias, comércio e serviços que fechavam as portas.

Hoje, além do êxodo rural que tem contribuído para o aumento da população urbana do município, houve uma redução das migrações inter-regionais (especialmente para São Paulo e Rio de Janeiro) que são, cada vez mais, uma última opção para a população local que não encontra sustento econômico. A emigração ainda ocorre, mas em ritmo mais lento e com novos destinos como Fortaleza e Sobral que, nas últimas décadas, receberam muitas indústrias e serviços que servem de atrativos à população mais carente de Cariré e de outras cidades pequenas do Norte Cearense.

A busca de empregos e serviços nas cidades maiores e mais próximas altera a dinâmica dos fluxos migratórios na rede urbana regional, levando ao aumento das migrações sazonais e pendulares (diárias), em detrimento das migrações definitivas para o Centro-Sul do país. O crescimento da metrópole e da capital regional também tem atraído as migrações de retorno dos carireenses que passam a residir, sobretudo na cidade e nas vilas. Esses fatos justificam, em parte, o afluxo populacional registrado no município entre 1991 e 2000 (Tabela 1).

Contudo, eles são, na grande maioria, fatos externos que influenciam na dinâmica demográfica de Cariré, fazendo com que essa cidade pequena fique mais dependente de cidades maiores como Sobral e Fortaleza. Na escala intra-urbana, nenhuma mudança significativa foi registrada nos últimos anos que conseguisse retomar seu crescimento econômico. A elite política local permanece "inerte", reproduzindo as tradicionais relações de poder e de exclusão da maioria da população.

A área central da cidade materializa a decadência das suas formas comerciais (mercado público, bodegas, feira livre, mercearias e armarinhos) e a crise econômica vivenciada no município desde a queda da produção algodoeira.

O centro da cidade perde importância comercial e econômica para outros bairros que já descentralizam alguns estabelecimentos comerciais para a "periferia", como é o caso do Açude Novo e Campo de Aviação, onde se concentra grande parte da população expulsa do campo. Nestes bairros, os mercantis e armazéns de materiais de construção encontrados, dispõem de uma infra-estrutura superior aos do centro da cidade.

De acordo com os comerciantes entrevistados, este fato se justifica pelo baixo poder aquisitivo da população dos bairros em apreço que concentra seu consumo no comércio local. Por isso, podemos dizer que a descentralização do comércio em Cariré não reflete uma "saturação do centro" ou uma "deseconomia de aglomeração". Esses processos são mais 
freqüentes nas áreas centrais das cidades médias e metrópoles, onde, dentre outros fatores, o elevado preço da terra e os congestionamentos, reduzem, ao logo do tempo, a taxa de lucro auferida pela localização no núcleo urbano (CORRÊA, 2002).

Por conseguinte, a população da área central (que tem um melhor poder aquisitivo e mais facilidades de deslocamento) deixa o comércio do centro para comprar em Sobral.

O comércio do centro arrefece, demonstrando a estagnação que domina a economia de Cariré e que é sentida pela população local, como arremata um morador no depoimento abaixo:

No comércio de Cariré não mudou quase nada. A gente observa que surgiu alguns mercantis que não tinha antes. Mas, isto não é mudar. Mudar é quando surge uma indústria, uma fábrica que gere emprego. Aí alguém pode montar um supermercado grande, que tem pra quem vender. Aqui tem um mercadinho aqui, outro ali... Mudou pouca coisa e não pode mudar muito porque aqui não tem nada (Morador, 47 anos).

\section{CONSIDERAÇÕES FINAIS}

Os depoimentos e as reflexões apresentadas demonstram que a pequena cidade de Cariré vem perdendo o vigor econômico que tivera outrora. Semelhante a Cariré, outros pequenos centros do Norte Cearense sofrem com a modernização "desigual" do campo que atingiu de forma particular a produção de algodão que era o grande esteio econômico de toda a região.

A crise econômica se instaura nas pequenas cidades da hinterlândia de Sobral, influenciando no decréscimo do comércio e dos serviços básicos de atendimento à população. Elas mesclam três dos cinco padrões funcionais propostos por Corrêa (2007) e citados anteriormente: núcleos dependentes de recursos externos; cidades subúrbios-dormitórios e focos de concentração de trabalhadores agrícolas.

Em Cariré, há a combinação desses três padrões, pois desde o colapso da cotonicultura, em meados dos anos de 1950, outras atividades não foram plenamente desenvolvidas para "alavancar" sua economia. Isto, inclusive, tem colaborado para o "desmonte" do parco setor terciário que existe, com o fechamento de muitos estabelecimentos comerciais e de serviço, além do decréscimo populacional registrado nas últimas décadas.

A descentralização do comércio que ocorre em Cariré é mais uma das facetas da crise econômica que assola o município e que dificulta o deslocamento da população mais pobre dos distritos e bairros mais distantes em direção à sede do município ou às cidades maiores. 
Portanto, essa realidade de Cariré (que se reproduz em outros pequenos centros do Norte Cearense, bem diferentes de muitos do Sul-Sudeste do país) demonstra a complexidade e os diferentes papéis das cidades pequenas na rede urbana brasileira, as quais precisam ser mais investigadas nas suas especificidades e diversidades regionais.

\section{REFERÊNCIAS}

AMORA, Zenilde Baima. O espaço urbano cearense: breves considerações. In: AMORA, Zenilde B. (Org.). O Ceará: enforques geográficos. Fortaleza: FUNECE, 1999.

ASSIS, Lenilton Francisco de. As redes de comércio e de serviços entre a cidade média de Sobral e algumas cidades pequenas da Região Norte do Ceará. In: ENCONTRO DE GEÓGRAFOS DA AMÉRICA LATINA, 10., 2005, Anais eletrônicos... São Paulo: USP, 2005. p. 1270-1291.

ASSIS, Lenilton Francisco de; ARAÚJO, Francinelda Ferreira de; GOMES, Maria Ferreira. A terciarização da cidade média de Sobral e sua influências no comércio das cidades pequenas de Cariré e Varjota-CE. Revista da Casa da Geografia de Sobral. v. 8/9, p. 123140, Disponível em: http://www.uvanet.br/rcg Acesso em: 12 dez. 2007

BRAGA, Roberto. A urbanidade das pequenas cidades. Disponível em: http:IIns.rc.unesp.br/igce/planejamento/territorioecidadania/Artigos/Braga\%2060.htm Acesso em: 20 out. 2004.

CEARÁ. Governo do Estado. Instituto de Pesquisa e Estratégica Econômica do Ceará (IPECE). Perfil Básico Municipal - Cariré. Disponível em: http://www.ipece.ce.gov.br Acesso em: 06 maio 2005.

CORRÊA, Roberto Lobato. Globalização e reestruturação da rede urbana - uma nota sobre as pequenas cidades. Revista Território, ano IV, n. 6. Rio de Janeiro: UFRJ, jan./jun, p. 43-53, 1999.

. Trajetórias geográficas. 2. ed. Rio de Janeiro: Bertrand Brasil, 2001.

. O espaço urbano. 4. ed. Ática. São Paulo, 2002.

Perspectivas da urbanização brasileira - uma visão geográfica para o futuro. In: SIMPÓSIO NACIONAL DE GEOGRAFIA URBANA, 10. 2007, Anais eletrônicos..., Florianópolis: UFPR, 2007. 1 CD.

FRESCA, Tânia Maria. Em defesa dos estudos das cidades pequenas no ensino de Geografia. Geografia, Londrina, v. 10, n. 1, p. 27-34, jan./jun. 2001.

GONÇALVES, Francisco Eduardo; DANTAS, Geovany. As feiras livres e a economia das cidades pequenas no Rio Grande do Norte. In: SIMPÓSIO NACIONAL DE GEOGRAFIA URBANA, 9. 2005, Anais eletrônicos..., Manaus: UEA, UFAM, AEB - Manaus, outubro 2005. 1 CD. 
HOLANDA, Virgínia Célia Cavalcante de. Dinâmica sócio-espacial de uma cidade média/Sobral-CE. 2000. 123 f. Dissertação (Mestrado em Geografia) - Centro de Ciências e Tecnologia, Universidade Estadual do Ceará. Fortaleza, 2000.

IBGE. Instituto Brasileiro de Geografia e Estatística. Banco de dados agregados - SIDRA. Disponível em: http://www.sidra.ibge.gov.br Acesso em: 23 mar. 2008

ISSLER, Bernardo. As feiras no Nordeste e sua função regional. Revista Orientação. Instituto de Geografia da Universidade de São Paulo. São Paulo, março/1967. p. 37-41

MARIA JÚNIOR, Martha. Cidades médias: uma abordagem da urbanização cearense. 2003. 104 f. Dissertação (Mestrado em Geografia) - Centro de Ciências e Tecnologia, Universidade Estadual do Ceará. Fortaleza, 2004.

MEDEIROS, Maria Auxiliadora de. A quebra do sistema produtivo do semi-árido: o caso de Cariré. 2000. 93 f. Monografia (Bacharelado em Geografia) - Centro de Ciências Humanas, Universidade Estadual Vale do Acaraú. Sobral, 2000.

OLIVEIRA, Bianca Simoneli de; SOARES, Beatriz Ribeiro. Cidades locais do Triângulo Mineiro e Alto Paranaíba/MG: algumas considerações. Caminhos de Geografia 3(5), p. 5272. Uberlândia: UFU, fev/2002.

PINTAUDI, Silvana Maria. A cidade e as formas de comércio. In: CARLOS, Ana Fani Alessandri (Org.). Novos caminhos da Geografia. São Paulo: Contexto, 2002. p.143-159. (Caminhos da Geografia)

SANTOS, Milton. $O$ espaço dividido: os dois circuitos da economia urbana dos países subdesenvolvidos. Rio de Janeiro: Francisco Alves, 1979.

. Espaço e sociedade (Ensaios). 2. ed. Petrópolis: Vozes, 1982.

. Técnica, espaço, tempo: globalização e meio-técnico-científico-informacional. 4. ed. São Paulo: Hucitec, 1998.

A urbanização brasileira. 5. ed. São Paulo: EDUSP, 2005.

SILVA, José Borzacchiello da. O algodão na organização do espaço. In: SOUSA, Simone (Org.). História do Ceará. Fortaleza: Demócrito Rocha, 2000. p. 81-92

SOARES, Beatriz Ribeiro; MELO, Nágela Aparecida de. Pequenas cidades: uma revisão do tema. In: SIMPÓSIO NACIONAL DE GEOGRAFIA URBANA, 9. 2005, Anais eletrônicos..., Manaus: UEA, UFAM, AEB - Manaus, outubro 2005. 1 CD.

VEIGA, José Eli da. Cidades imaginárias: o Brasil é menos urbano do que se calcula. Campinas, SP: Autores Associados, 2002.

WANDERLEY, Maria de Nazareth Baudel. Urbanização e ruralidade: relações entre a pequena cidade e o mundo rural; Estudo preliminar sobre os pequenos municípios em Pernambuco. Disponível em: http://www.fundaj.gov.br/pbservanordeste/obed001f.doc Acesso em: 07 dez. 2001

(Recebido em novembro/08. Aceito em dezembro/08) 